\title{
Corrigendum: Evidence in Practice - a Pilot Study Leveraging Companion Animal and Equine Health Data From Primary Care Veterinary Clinics in New Zealand
}

\begin{abstract}
Petra Muellner ${ }^{1 *}$, Ulrich Muellner ${ }^{1}$, M. Carolyn Gates ${ }^{2}$, Trish Pearce ${ }^{3}$, Christina Ahlstrom ${ }^{1}$, Dan O'Neill ${ }^{4}$, Dave Brodbelt ${ }^{4}$ and Nick John Cave ${ }^{2}$

'Epi-interactive Ltd., Wellington, New Zealand, ${ }^{2}$ Institute of Veterinary, Animal and Biomedical Sciences, Massey University, Palmerston North, New Zealand, ${ }^{3}$ Equine Health Association, Wellington, New Zealand, ${ }^{4}$ The Royal Veterinary College, Hatfield, United Kingdom
\end{abstract}

Keywords: surveillance, veterinary, primary care, early warning, interface design, IT, companion animal, equine

\section{OPEN ACCESS}

Edited and reviewed by: Frontiers in Veterinary Science, Frontiers Media SA, Switzerland

${ }^{*}$ Correspondence: Petra Muellner petra@epi-interactive.com

Specialty section: This article was submitted to Veterinary Epidemiology and Economics,

a section of the journal Frontiers in Veterinary Science

Received: 05 October 2021 Accepted: 06 October 2021 Published: 01 November 2021

Citation:

Muellner P, Muellner U, Gates MC Pearce T, Ahlstrom C, O'Neill D, Brodbelt D and Cave NJ (2021) Corrigendum: Evidence in Practice - a

Pilot Study Leveraging Companion Animal and Equine Health Data From Primary Care Veterinary Clinics in New

Zealand. Front. Vet. Sci. 8:789718. doi: 10.3389/fvets.2021.789718

\section{A Corrigendum on}

Evidence in Practice - A Pilot Study Leveraging Companion Animal and Equine Health Data From Primary Care Veterinary Clinics in New Zealand

by Muellner, P., Muellner, U., Gates, M. C., Pearce, T., Ahlstrom, C., O’Neill, D., et al. (2016). Front. Vet. Sci. 3:116. doi: 10.3389/fvets.2016.00116

In the original article, the Conflict of Interest Statement was incomplete. The corrected statement appears below.

"The Handling Editor AP declared a past co-authorship with the author PM and states that the process nevertheless met the standards of a fair and objective review.

The remaining authors declare that the research was conducted in the absence of any commercial or financial relationships that could be construed as a potential conflict of interest."

The authors apologize for this error and state that this does not change the scientific conclusions of the article in any way.

Publisher's Note: All claims expressed in this article are solely those of the authors and do not necessarily represent those of their affiliated organizations, or those of the publisher, the editors and the reviewers. Any product that may be evaluated in this article, or claim that may be made by its manufacturer, is not guaranteed or endorsed by the publisher.

Copyright $\odot 2021$ Muellner, Muellner, Gates, Pearce, Ahlstrom, O'Neill, Brodbelt and Cave. This is an open-access article distributed under the terms of the Creative Commons Attribution License (CC BY). The use, distribution or reproduction in other forums is permitted, provided the original author(s) and the copyright owner(s) are credited and that the original publication in this journal is cited, in accordance with accepted academic practice. No use, distribution or reproduction is permitted which does not comply with these terms. 